\title{
LAPAROSCOPIC TREATMENT OF RETROPERITONEAL FIBROSIS: REPORT OF TWO CASES AND REVIEW OF THE LITERATURE
}

\author{
Lísias Nogueira Castilho, Anuar Ibrahim Mitre, Flávio Haruyo Iizuka, Oscar \\ Eduardo Hidetoshi Fugita, José Roberto Colombo Jr. and Sami Arap
}

RHCFAP/3006

CASTILHO L N et al. - Laparoscopic treatment of retroperitoneal fibrosis: report of two cases and review of the literature. Rev. Hosp. Clín. Fac. Med. S. Paulo 55(2):69-76, 2000.

SUMMARY: Objectives: We present the results of treatment by laparoscopy of two patients with retroperitoneal fibrosis and review the literature since 1992, when the first case of this disease that was treated using laparoscopy was published. We also discuss the contemporary alternatives of clinical treatment with corticosteroids and tamoxifen.

Case report: Two female patients, one with idiopathic retroperitoneal fibrosis, and other with retroperitoneal fibrosis associated with Riedel's thyroiditis, were treated using laparoscopic surgery. Both cases had bilateral pelvic ureteral obstruction and were treated using the same technique: transperitoneal laparoscopy, medial mobilization of both colons, liberation of both ureters from the fibrosis, and intraperitonealisation of the ureters. Double-J catheters were inserted before the operations and removed 3 weeks after the procedures. The first patient underwent intraperitonealisation of both ureters in a single procedure. The other had 2 different surgical procedures because of technical difficulties during the first operation. Both patients were followed for more than 1 year and recovered completely from the renal insufficiency. One of them still has occasional vague lumbar pain. There were no abnormalities in the intravenous pyelography in either case.

Conclusions: Surgical correction of retroperitoneal fibrosis, when indicated, should be attempted using laparoscopy. If possible, bilateral ureterolysis and intraperitonealisation of both ureters should be performed in the same operation.

DESCRIPTORS: Retroperitoneal fibrosis. Ureteral intraperitonealisation. Ureterolysis.

Retroperitoneal fibrosis was first described by French urologist Albarran at the beginning of the century and has received countless other names through time: Ormond's disease, fibrotic periureteritis, plastic periureteritis, chronic periureteritis, sclerosing retroperitoneal granuloma, fibrotic retroperitonitis, perianeurismatic retroperitoneal fibrosis, subclinical chronic periaortitis, and chronic periaortitis ${ }^{1,2}$. Until recently, different etiopathogenic conditions were grouped under the name of retroperitoneal fibrosis which generated confusion in medical literature. Current practice is to classify retroperitoneal fi- brosis into 2 groups: idiopathic and secondary ${ }^{1}$. Idiopathic retroperitoneal fibrosis (IRF), which comprises to twothirds of the total cases, is retroperitoneal fibrosis in which no etiology can be defined and that does not associate itself to any other etiopathogenic condition (Table 1). Secondary retroperitoneal fibrosis (SRF) is associated with cancer, drugs, chemical products, infections, inflammatory diseases, retroperitoneal bleeding, or radiotherapy ${ }^{1}$.

From the Division of Urology, Hospital das Clínicas, Faculty of Medicine, University of São Paulo.
IRF afflicts all races equally, being predominant in the male sex in the proportion of $2: 1$ to $3: 1$, with its peak of incidence being between 40 and 60 years of age $e^{4}$. There is evidence that the onset of IRF depends on hereditary predisposition, and may have an etiologic relation with the arteriosclerotic process of the terminal aorta and the iliac arteries ${ }^{1,5,6}$. IRF has an initially insidious and vague clinical presentation with symptoms being malaise, lumbar pain, anorexia, low fever, and asthenia. Of these, the most frequent, which must therefore be emphasized, is lumbar pain, which is present in $80 \%$ to 
Table 1 - Retroperitoneal fibrosis: etiology in 491 patients*

\begin{tabular}{lr}
\hline Etiology & Percent \\
\hline Idiopathic & 67.8 \\
Methysergide & 12.4 \\
Malignancies & 7.9 \\
Mediastinal fibrosis & 3.3 \\
Periaortic inflammation & 2.4 \\
Mesenteric fibrosis & 2.0 \\
Sclerosing cholangitis & 1.6 \\
Aortic abdominal aneurism & 1.6 \\
Crohn's disease & 1.2 \\
Thrombophlebitis & 1.0 \\
Riedel's thyroiditis & 0.8 \\
Other & 5.3 \\
\hline
\end{tabular}

* Modified from Koep \& Zuidema ${ }^{3}$

$90 \%$ of the cases; however, this symptom is not diagnostic. With the evolution of the disease, manifestations indicative of renal insufficiency due to bilateral ureteral compression, such as hypertension, edema and anemia, or even signs caused by the compression of retroperitoneal veins, such as edema of the lower limbs, varicocele, and hydrocele $^{1,4}$ may appear. Diagnosis of IRF in its initial phase is very difficult because the physical examination of the patient is usually normal and the clinical laboratory findings are nonspecific, the most constant being the elevation of ESR (erythrocyte sedimentation rate) present in over $80 \%$ of the cases. ${ }^{2}$ The clinical diagnosis depends fundamentally on the demonstration, by computerized tomography (CT) or, preferably, magnetic nuclear resonance (MRI) ${ }^{7}$, of a unilateral, or, far more frequently, bilateral thickening of the retroperitoneum, which may extend vertically from the renal hilum to the pelvic brim, and laterally from one psoas muscle to the other. In the majority of cases, the fibrotic retroperitoneal thickening is located between the last lumbar vertebrae and the first sacral vertebrae, in the region of the aor- tic bifurcation, sparing the posterior region of the great vessels. The medial deviation of the ureters in their middle portion is typical, however non-pathognomonic, as is the approximation of the aorta and the vena cava, in opposition to what occurs in malignant metastatic diseases, in which augmented interaortocaval lymph nodes promote distancing of the great vessels ${ }^{8}$.

The treatment of IRF is controversial, not only because the natural history of the disease is not well known due to its low incidence, estimated by some to be $1 / 200000$ inhabitants ${ }^{9}$, but also because there are reports of spontaneous regression ${ }^{10}$ and favorable responses to several different pharmaceutical treatments with corticosteroids, tamoxifen, azatioprin, methotrexate, cyclophosfamide, and penicillamine, used alone or in combination, with or without concomitant use of Double-J ureteral catheters ${ }^{1,11}$. Unfortunately, all reports of clinical treatment involve small numbers of patients and are not controlled studies; for this reason, many urologists, claiming good results in the long run, have opted for immediate surgical treatment, once the diagnosis is established ${ }^{1,2,5,12}$. Surgical treatment consists basically in unilateral or bilateral ureterolysis. Some defend bilateral treatment in all cases, even if there are no radiological evidences of involvement of both ureters. ${ }^{1}$ The ureterolysis is the liberation of all the incarcerated portion of the ureter, which is usually involved by a circular concentric fibrosis, from its proximal healthy portion to the distal portion, generally free of fibrosis, below the iliac vessels. The ureteral liberation, as an isolated procedure, can lead to relapse, hence the preference of the majority of surgeons for wrapping the ureters with retroperitoneal fat or greater omentum, or, alternatively, intraperitonealisation them ${ }^{1,2,9}$. Whenever possible, whether to alleviate renal insufficiency, reducing the risk of com- plications, or to facilitate the ureteral identification and dissection, a Double$\mathbf{J}$ catheter is introduced in each of the ureters, days or weeks before surgery, remaining there for 2 to 3 weeks after surgery ${ }^{9}$.

Open surgery has been traditionally performed through a median transperitoneal incision. Some prefer opening the retroperitoneum through a median incision in the posterior peritoneum, beginning superiorly between the duodenum and the inferior mesenteric vein, others opt to incise the line of Toldt, mobilizing the colons medially ${ }^{1,2}$. Both retroperitoneal approaches allow ureterolysis, the envelopment of the ureters with fatty tissue followed by intraperitonealisation. The open surgery has approximately $9 \%$ mortality and $60 \%$ morbidity, either because the patients frequently present chronic renal insufficiency and poor clinical conditions, or because of the extent of the surgery ${ }^{9}$.

When possible, the underlying disease of SRF is treated. When this is not possible, the clinical or surgical treatment for IRF can be performed, with similar results ${ }^{2,9,12}$.

Since 1992, several cases of laparoscopic ureterolysis and intraperitonealisation have been described, with low morbidity rates and no deaths reported ${ }^{9,13-18}$. Elashry, et al compared the results of 6 laparoscopic surgeries with 7 open surgeries, all unilateral ureterolysis cases, and concluded that the laparoscopic approach is superior in all considered aspects, with the only exception being mean surgical time: 255 minutes for the laparoscopy versus 232 minutes for the open surgery ${ }^{9}$. Because of these reports and our previous experience with laparoscopic technique, we decided to evaluate the results of laparoscopic intraperitonealisation in retroperitoneal fibrosis cases and also review the medical information related to the treatment of retroperitoneal fibrosis. 


\section{CASE REPORTS}

\section{Surgical technique}

The patient undergoing single-stage bilateral intraperitonealisation of the ureters lies on the operating table in dorsal decubitus, with arms extended alongside the body, under general anesthesia. Initially, only 4 trocars are used, but more may be inserted depending on the difficulty of the surgery and the extent of the ureteral fibrosis. The trocars are inserted in the abdomen based on the extent of the intended dissection. In bilateral intraperitonealisation with ureteral segments incarcerated in the sacrolumbar area, a $10 \mathrm{~mm}$ trocar is inserted through the umbilical scar (for the optic), a $5 \mathrm{~mm}$ trocar is inserted in the hemiclavicular line on each side, 2-3 centimeters below the umbilical scar, and a $10 / 11 \mathrm{~mm}$ trocar is inserted in the median line, $2 \mathrm{~cm}$ above the pubis. Once the trocars are inserted and the cavity is inspected, the procedure begins.

An incision in the parietal peritoneum is made laterally to the line of Toldt, so as to leave a $2 \mathrm{~cm}$ free peritoneum band connected to the colon, to be later sutured or clipped to the lateral border of the peritoneum. The colon is mobilized medially (which side first is irrelevant), to expose the Gerota's fascia and the ureter. The healthy ureteral segment, distal or proximal, is approached first and placed under light traction with a thin Penrose drain to facilitate the dissection. The presence of a Double-J catheter inserted prior to surgery greatly diminished the difficulty of this maneuver. The incarcerated segment of the ureter is dissected and freed from the fibrosis in its full extent until the normal portion of the ureter is reached (either proximal or distal). Once mobilized, the ureteral segment is placed anteriorly to the borders of the incised parietal peritoneum, which are ap-

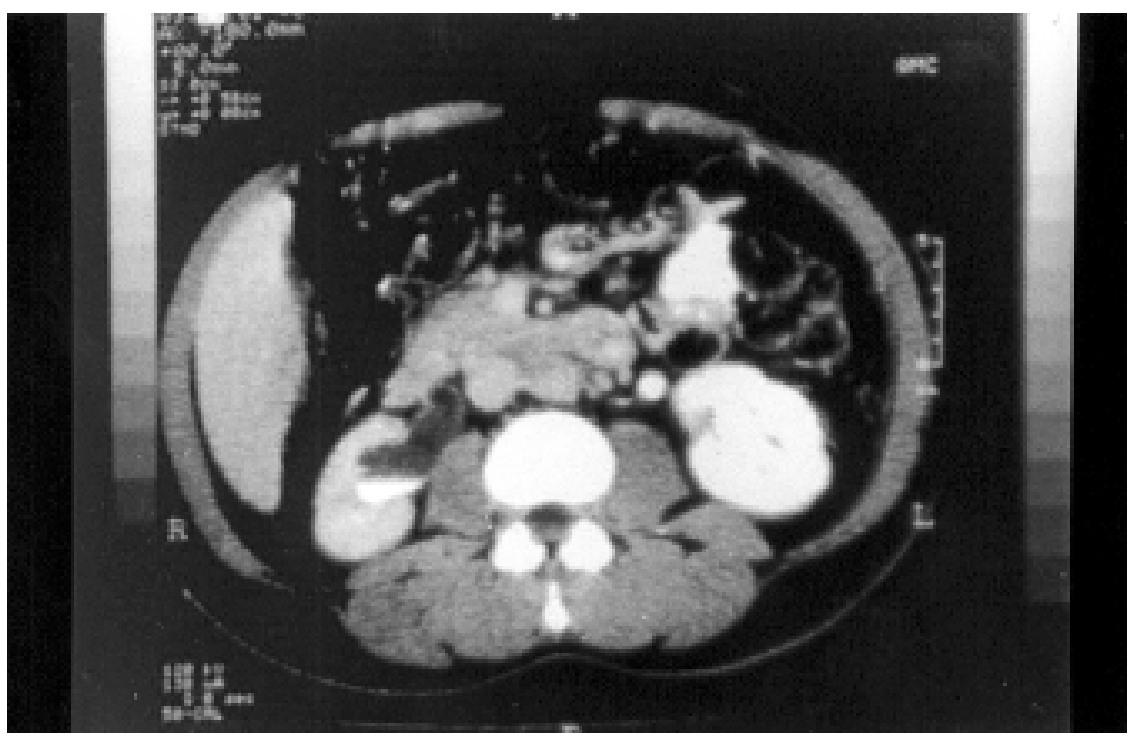

Figure 1 - Abdominal CT shows a retroperitoneal thickening anterior to the great vessels, and bilateral hydronephrosis.

proximated with sutures or metallic clips, depending on the availability of the material and the surgeon's preference. Care is taken not to leave the ureter angled or narrowed in the entrances to the retroperitoneum, proximally and distally. The procedure is repeated in the contralateral side, and the surgery is finalized. Both ureteral catheters are removed 3 weeks after the surgery.

Two patients with retroperitoneal fibrosis who had been sent for bilateral intraperitonealisation through laparotomy were selected for laparoscopic surgery. After the informed consent of both, the surgeries were performed.

\section{Case 1}

G.P.N., white female, 58 years old, born in Piatá (BA), went to the ER of the Hospital das Clinicas da FMUSP in April 1996 with intermittent bilateral lumbar colics, and occasional fever. She had antecedents of idiopathic hypothyroidism, arterial hypertension, and diabetes mellitus, adequately treated. At this occasion, her physical examination was normal. She underwent routine clinical laboratory tests, which were all normal, except for se- rum creatinine $(C=2.0)$. She then took an abdominal echography, revealing bilateral ureterohydronephrosis. Then, under local anesthesia, a retrograde bilateral ureteropyelography was performed; its result was suggestive of extrinsic ureteral obstruction (L4-L5 region), with medial deviation of the ureters in their middle portions. In the same procedure, Double-J catheters were introduced bilaterally with no difficulties. After a few weeks, serum creatinine fell to 1.2 , and the patient did not present further complaints. The CT revealed a thickening of the retroperitoneum anterior to the great vessels, between L4 and S1, suggesting retroperitoneal fibrosis (Fig. 1). On 7-30-1996 the laparoscopic bilateral ureteral intraperitonealisation was performed.

The surgical procedure took 3 hours and 35 minutes, and there were no intra or post-operative complications. Bleeding was negligible. The patient was discharged on the 3rd postoperative day, reporting practically no pain. The catheters were removed 3 weeks after the surgery, and a bilateral pyelography was performed to visualize the ureters (Fig. 2). She was then 

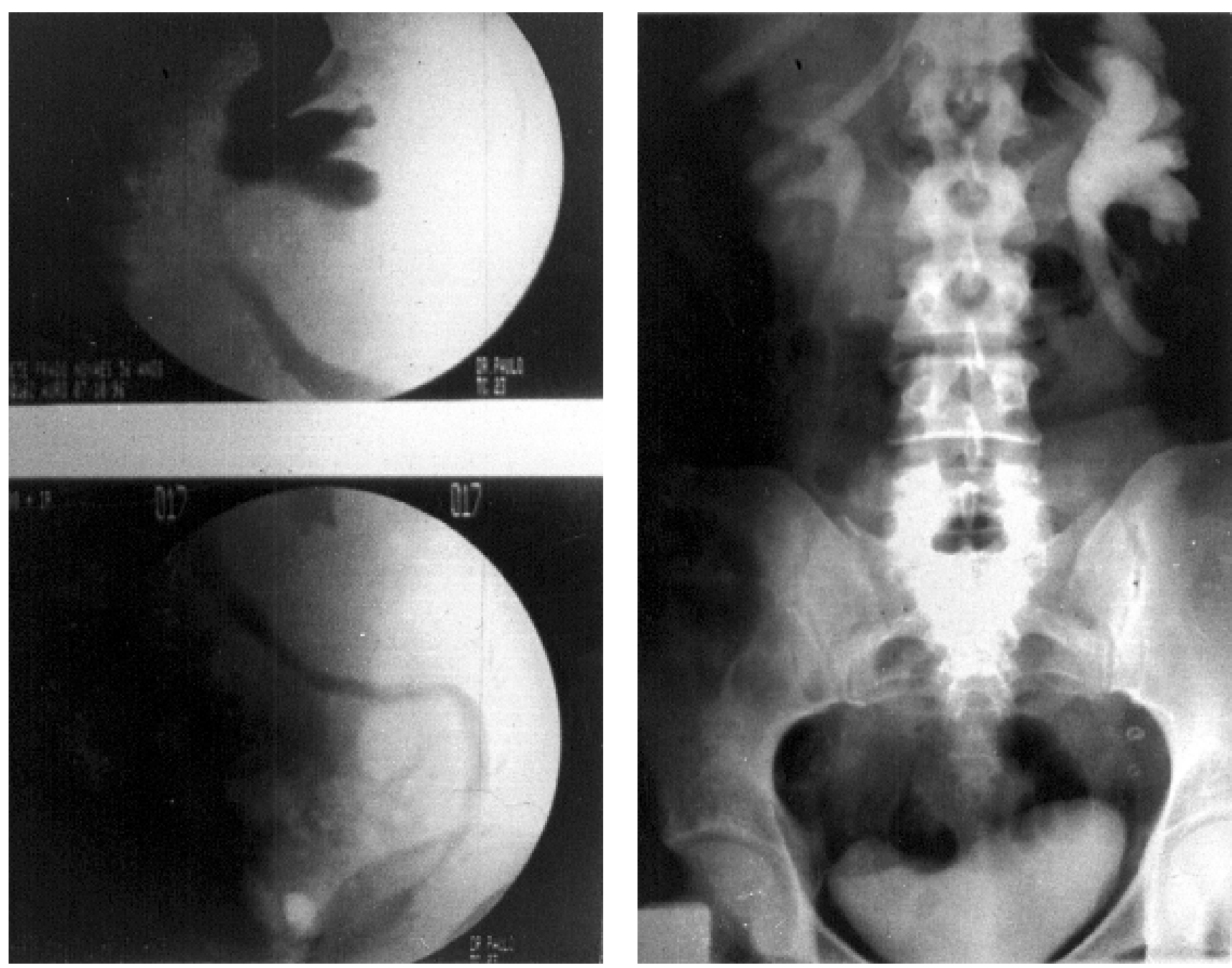

Figure 2 - Left retrograde ureteropyelography 4 weeks after the operation. One can observe pyeloureteral ectasy and an exaggerated ureteral lateralization. On the right side the image was similar.

Figure 3 - Intravenous pyelography 3 months after the operation. One can observe pyeloureteral ectasy, mainly on the left side.

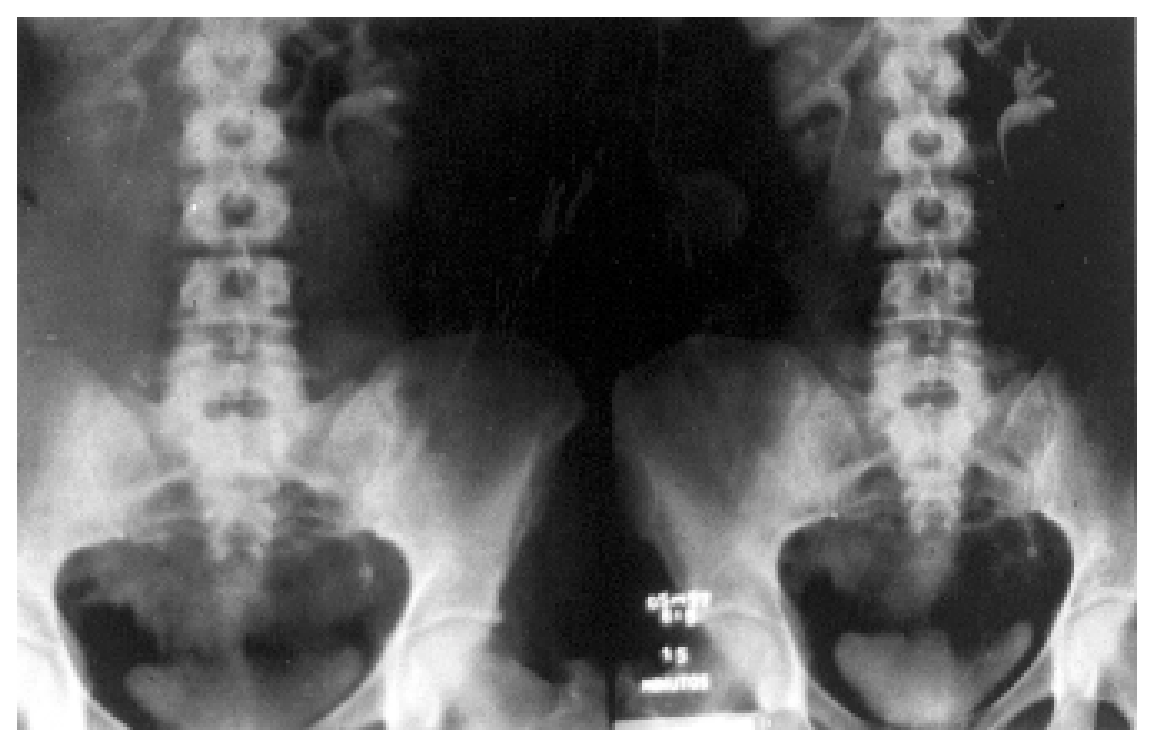

Figure 4 - Normal intravenous pyelography 1 year after the operation. 
followed with serum creatinine and intravenous pyelographies. The creatinine stabilized at 1.3 and the pyelographies 1 and 2 years after the surgery showed normal kidneys, absence of dilation, and ureteral lateralization (Figs. 3 and 4). The patient reports light lumbar pain on the right side, irradiated to the right inferior limb, which ceases with common analgesics.

\section{Case 2}

J.A.A., white female, 51 years old, born in Guararapes (SP), presented a sudden increase in the anterior cervical region, with fever and sweating, in October, 1996. Initially treated with antiinflammatories and antibiotics, she underwent clinical laboratory tests until February, 1997, when the diagnosis of hypothyroidism was established and the treatment with T3 and T4 initiated. In 1997, she presented bilateral lumbar pain and dysuria. Her physical examination at the occasion had a single abnormality: augmented thyroid with petrous consistency. The abdominal echography revealed bilateral ureterohydronephrosis. Serum creatinine was 4.4, and the CT was suggestive of retroperitoneal fibrosis. On 9-26-1997, an attempt to pass Double-J catheters bilaterally was unsuccessful, and two thin ureteral catheters externally connected to a Foley catheter were left in place. Two weeks later it was possible to substitute each catheter for a Double-J. On the 10-21-1997, the patient underwent a laparoscopic procedure for retroperitoneal biopsies and bilateral ureteral intraperitonealisation. The ureterolysis of the left side was easy, and the intraperitonealisation was completed. However, on the right side, the fibrotic process was far more intense and did not allow the identification of the ureter or of the iliac vessels. Four hours after the start of the surgery, the choice was made for a direct ureterolysis on another occasion. In the same anesthetic session, a thyroid biopsy was performed, confirming clinical suspicion of Riedel's thyroiditis. The retroperitoneal biopsies revealed only an unspecific inflammatory process. The patient was discharged on the 10 th post-operative day, with no complications. There was no need for blood transfusion. The late discharge was due to social problems of the patient; clinically, she could have left the hospital on the 2nd or 3rd post-operative day. Due to the extensive fibrosis on the right side, involving not only the ureter but also the psoas muscle and the iliac vessels, treatment with prednisone (40 mg/day) and tamoxifen $(20 \mathrm{mg} /$ day) for 3 months was initiated. On the 02-09-98, the patient successfully underwent laparoscopic ureterolysis and intraperitonealisation on the right side. During the surgery, it was observed that the fibrosis extended up to the renal fossa. The renal pelvis was accidentally opened and closed with an intracorporeal suture using chromic catgut 4-0.

In this case, the first surgery took 4 hours; the second, 3 hours and 15 minutes. Bleeding was negligible in both procedures, and the patient was discharged in the 10th and 5th post-operative day, respectively. Both ureteral catheters were removed three weeks after the second surgery. After a year of follow-up, the patient had no abdominal or lumbar pain, serum creatinine stabilized at 1.4 and the intravenous pyelography was normal.

In none of the 3 procedures was any form of drainage used in the abdominal cavity.

\section{DISCUSSION}

Due to the relative rarity of retroperitoneal fibrosis, there are few reports in medical literature that present more than a dozen cases originated in the same service, and even then, these are non-randomized and lack control groups. The reports with the greatest data are usually product of literature reviews and suffer from the same limitations ${ }^{4}$. In face of available published data, it can be said that not much is known yet about the natural history of retroperitoneal fibrosis, nor about the most appropriate treatment for patients. It is also impossible to determine where clinical treatment attempts should end and in which circumstances should surgical treatment begin. There are those who defend the superiority of clinical treatments ${ }^{11}$, and those who choose surgery as the best option ${ }^{5,12}$; however, in neither case is there rigorous scientific basis. Due to the good results obtained by some with corticoid treatment, in doses (determined empirically) of 20 to $60 \mathrm{mg}$ of prednisone a day during several weeks, or with tamoxifen, $20 \mathrm{mg}$ a day during several months (dosage also determined empirically), and eventually used in association, it can be argued that the clinical treatment should be primarily attempted in IRF and in some forms of $\mathrm{SRF}^{11}$. Tamoxifen, used in IRF since $1991^{19}$, has intense antiestrogenic action, and its usefulness in breast cancer is beyond question. However, even in cases where there are no estrogenic receptors, tamoxifen seems to work, inhibiting the proliferation of fibroblasts, hence its utilization in fibrotic diseases and mesenchymal tumors ${ }^{20-23}$.

In non-malignant IRF and SRF, retroperitoneal biopsies can reveal different degrees of inflammatory cellularity, which suggests different stages in the fibrotic formation process. Theoretically, the greater the cellularity, the greater the probability of corticoids reverting the process and avoiding the fibrosis. Once the fibrosis is established in greater or lesser degree, tamoxifen seems to have some effect, hence the theoretical utility of the combined use of corticosteroids and tamoxifen in cases in which the pathology demon- 
strates high degree of inflammatory cellularity, or only tamoxifen, when the fibrosis is predominant. As a way to optimize the clinical treatment, systematic biopsies to ascertain non-malignancy and also to determine the degree of inflammatory cellularity has been suggested by some clinicians. Others suggest treatment with corticosteroids in the post-operative period ${ }^{2,5,20,23}$.

Not all cases respond to clinical treatment; these must treated surgically. Open surgery has significant morbidity and mortality ${ }^{1,9}$. Since 1992, laparoscopic technique has been successfully performed by some groups, with results apparently comparable to those of open surgery, but having lower incidence of complications with no deaths reported due to the surgical procedure $^{13}$. In the treatment of unilateral ureteral incarceration, Elashry et $\mathrm{al}^{9}$ concluded that laparoscopic surgery was superior to open surgery, despite requiring a few more minutes on average to perform. His study compared 6 cases of unilateral fibrosis, only 2 of which having an IRF diagnosis, with 7 historical cases of fibrosis, also unilateral, 2 of which were associated with aortic aneurysms and 1 with a total hysterectomy. His conclusions can be questioned, as they are based on a small data set, noncomparable groups, and a majority of SRF cases. Although there are no groups with large experience in laparoscopically corrected SRF yet, those that have performed it have had the impression, based also on the expe- rience of successful laparoscopic treatment of other retroperitoneal diseases, such as adrenalectomy and nephrectomy, that laparoscopy is the method of choice in retroperitoneal fibrosis.

Ureterolysis, performed as an isolated procedure, probably has more frequent recurrences, which is why most surgeons perform the complimentary ureteral intraperitonealisation, with or without involvement of greater omentum, with superior results. Some proceed empirically with pharmaceutical treatment after successful surgery as prophylaxis of recurrence ${ }^{1,2,5,11}$. Some investigators have also empirically determined that the Double-J catheters must remain for 2 to 3 weeks after surgery.

In the two patients we had the opportunity to treat and follow, we made no attempt to treat primarily with corticosteroids and/or tamoxifen before prescribing surgery, because these cases were initially considered advanced and had already been selected for open surgery by other colleagues. However, considering the international experience with clinical treatment, today the handling of the cases could have possibly been different. After the Double-J catheters had been passed, we would have attempted a clinical treatment with corticosteroids and tamoxifen for 3 or 4 weeks, and then reevaluated. In case of regression of the fibrosis, verified by CT or MRI, we would proceed for a few more weeks and then decide on whether to operate, based on the results. The empirical clinical treatment introduced in the second case, after the failed attempt to perform the ureterolysis on the right side, was not adequately evaluated, making conclusions unfeasible. The subjective intra-operative impression was of a slightly diminished fibrosis, which facilitated the dissection of the pelvic ureter, impossible in the first operation.

The association of retroperitoneal fibrosis with Riedel's thyroiditis, as in our second case, is very rare, and does not require any special therapeutic measure in the approach of retroperitoneal fibrosis ${ }^{3,24,25}$. Despite being etiologically classified as SRF, the patient was successfully treated as IRF.

The clinical evolution in both cases was excellent, the painful symptoms and the renal insufficiency having disappeared rapidly. However, the radiological evolution was slower, with pyeloureteral ectasy persisting for several months (Fig. 3). After a year of evolution, the radiologic images normalized completely in both cases, even though signs of retroperitoneal fibrosis persisted (Fig. 4).

In conclusion, although we do not yet know much about retroperitoneal fibrosis, its natural history, or the best treatment alternatives, when there is surgical indication, we understand that the laparoscopic intraperitonealisation is possibly the most appropriate technique for the patient, which may be confirmed in the next few years.
CASTILHO L N e col. - Tratamento laparoscópico de fibrose retroperitoneal: relato de dois casos e revisão da literatura. Rev. Hosp. Clín. Fac. Med. S. Paulo 55(2):69-76, 2000.
Objetivos: Os autores apresentam os resultados de dois pacientes com fibrose retroperitoneal tratados por laparoscopia e fazem a revisão da literatura desde 1992, quando o primeiro caso de fibrose retroperitoneal tratado laparoscopicamente foi publicado. Eles também discutem as alternativas terapêuticas contemporâneas de tratamento clínico com corticosteróides e tamoxifeno. 
Relato dos casos: Duas mulheres, uma com fibrose retroperitoneal idiopática, e a outra com fibrose retroperitoneal associada a tireoidite de Riedel, foram operadas por laparoscopia. Ambas apresentavam obstrução ureteral pélvica bilateral e foram operadas por meio da mesma técnica: laparoscopia transperitoneal, mobilização medial de ambos os cólons, liberação dos ureteres da fibrose e intraperitonização ureteral. Cateteres Duplo-J foram inseridos antes das ci- rurgias e removidos três semanas depois da intraperitonização. A primeira paciente teve os dois ureteres intraperitonizados em um único procedimento. A segunda foi submetida a dois procedimentos distintos por dificuldades técnicas durante a primeira cirurgia. Ambas foram acompanhadas por mais de um ano e recuperaram-se completamente da insuficiência renal. Uma delas ainda tem dor lombar leve ocasionalmente. As urografias excretoras de ambas as pa- cientes não apresentam mais anormalidades.

Conclusões: A correção cirúrgica da fibrose retroperitoneal, quando indicada, deve ser realizada por laparoscopia. A ureterolise e a intraperitonização de ambos os ureteres devem ser realizadas no mesmo ato cirúrgico, sempre que possível.

DESCRITORES: Fibrose retroperitoneal. Intraperitonização ureteral. Ureterolise.

\section{REFERENCES}

1. HALL MC, VON ESCHENBACH AC \& AMES CA - Diseases of the retroperitoneum. In: GILLENWATER JY, GRAYHACK JT, HOWARDS SS et al. (eds.) Adult and Pediatric Urology. St. Louis, Mosby, 1996. p. 1123.

2. RESNICK MI \& KURSH ED - Extrinsic obstruction of the ureter. In: WALSH PC, RETIK AB, VAUGHAN JR ED et al. (eds.) Campbell's Urology. Philadelphia, Saunders, 1996. p. 387.

3. KOEP L \& ZUIDEMA GD - The clinical significance of retroperitoneal fibrosis. Surgery 1977;81:250-257.

4. LEPOR H \& WALSH PC - Idiopathic retroperitoneal fibrosis. J Urol 1979,122:1-6.

5. DE LUCA S, TERRONE C, MANASSERO A et al. - Aetiopathogenesis and treatment of idiopathic retroperitoneal fibrosis. Ann Urol 1998;32:153-159.

6. ZDROJEWSKI Z - Retroperitoneal fibrosis and chronic peri-aortitis: a new hypothesis. Pol Merkuriusz Lek 1998;4:50-53.

7. ENGELKEN JD \& ROS PR - Retroperitoneal MR imaging. Magn Reson Imaging Clin N Am 1997;5:165-178.

8. BACHMANN G, BAUER T \& RAU WS - MRI and CT in diagnosis and follow-up of idiopathic retroperitoneal fibrosis. Radiology 1995;35:200-207.

9. ELASHRY OM, NAKADA SY, WOLF JR JSI et al. - Ureterolysis for extrinsic ureteral obstruction: a comparison of laparoscopic and open surgical techniques. J Urol 1996;156:1403-1410.

10. TOSCANO C, DI MARZO L, SAPIENZA P et al. - A case of retroperitoneal fibrosis with spontaneous regression. Minerva Chir 1997;52:1123-1127.
11. OOSTERLINCK W \& DERIE A - New data on diagnosis and medical treatment of retroperitoneal fibrosis. Acta Urol Belg. 1997;65:3-6.

12. MARTIN-MARQUINA A, RODRIGUEZ-RUBIO FI, ABAD JI, et al. - Idiopathic retroperitoneal fibrosis. Report of 12 cases. Actas Urol Esp 1995;19:303-306.

13. KAVOUSSI LR, CLAYMAN RV, BRUNT LM et al. - Laparoscopic ureterolysis. J Urol 1992;147:426-429.

14. PUPPO P, CARMIGNANI G, GALLUCI M et al. - Bilateral laparoscopic ureterolysis. Eur Urol 1994;25:82-84.

15. KAWABATA G, SHIMOGAKI H \& YAMANAKA N - Laparoscopic approach to idiopathic retroperitoneal fibrosis. Nippon Hinyokika Gakkai Zasshi 1995;86:1060-1063.

16. BOEKMANN W, WOLFF JM, ADAM G et al. - Laparoscopic bilateral ureterolysis in Ormond's disease. Urol Int 1996;56:133-136.

17. KAVA BR, RUSSO P \& CONLON KC - Laparoscopic diagnosis of malignant retroperitoneal fibrosis. J Endourol 1996;10:535-538.

18. MATTELAER P, BOEKMANN W, BRAUERS A et al. - Laparoscopic ureterolysis in retroperitoneal fibrosis. Acta Urol Belg 1996;64:1518 .

19. CLARK CP, VANDERPOOL D \& PRESKITT JT - The response of retroperitoneal fibrosis to tamoxifen. Surgery 1991;109:502-506.

20. OWENS LV, CANCE WG \& HUTH JF - Retroperitoneal fibrosis treated with tamoxifen. Am Surg. 1995;61:842-844.

21. BRÉCHIGNAC X, DE WAZIÈRES B, DESMURS H et al. - New medical treatments of systemic idiopathic fibrosis. Rev Med Interne 1997; 18:967-971. 
22. SAVELLI BA, PARSHLEY M \& MORGANROTH ML - Successful treatment of sclerosing cervicitis and fibrosing mediastinitis with tamoxifen. Chest 1997;111:1137-1140.

23. ALLENDORFF J, RIEGEL W \& KÖHLER H - Regression of retroperitoneal fibrosis by combination therapy with tamoxifen and steroids. Med Klin 1997;92:439-443.
24. MARCHESI M, BIFFONI M, MASTROPIETRO T et al. - Riedel's thyroiditis: a case report and review of the literature. G Chir 1997; 18:820-822.

25. JULIE C, VIEILLEFOND A, DESLIGNERES S et al. - Hashimoto's thyroiditis associated with Riedel's thyroiditis and retroperitoneal fibrosis. Pathol Res Pract. 1997; 193:573-577.

Received for publication on the $21 / 02 / 00$ 